\title{
One size does not fit all: the influence of individual and contextual factors on research excellence in academia
}

\section{Giacomo Carli, Maria Rita Tagliaventi \& Donato Cutolo}

To cite this article: Giacomo Carli, Maria Rita Tagliaventi \& Donato Cutolo (2019) One size does not fit all: the influence of individual and contextual factors on research excellence in academia, Studies in Higher Education, 44:11, 1912-1930, DOI: 10.1080/03075079.2018.1466873

To link to this article: https://doi.org/10.1080/03075079.2018.1466873

\section{Published online: 25 Apr 2018.}

Submit your article to this journal $\widetilde{x}$

LII Article views: 374

\section{Q View related articles $₫$}

View Crossmark data ¿

Citing articles: 3 View citing articles $\sqsubset$ 


\title{
One size does not fit all: the influence of individual and contextual factors on research excellence in academia
}

\author{
Giacomo Carli (iD) ${ }^{a}$, Maria Rita Tagliaventi (iD ${ }^{b}$ and Donato Cutolo (D) ${ }^{c}$ \\ ${ }^{a}$ Department of Strategy and Marketing, The Open University Business School, Milton Keynes, UK; ${ }^{b}$ Department of \\ Sociology and Business Law, University of Bologna, Bologna, Italy; 'Department of Management, University of \\ Bologna, Bologna, Italy
}

\begin{abstract}
Research excellence has been the main thrust of higher education reforms in several countries, but its translation into coherent policies has proved to be controversial. Literature has delved into the role exerted by contextual factors and individual characteristics in the adoption of behaviours inspired by social values. Our study aims at investigating the effect of individual and contextual features and their interplay in the quest for research excellence. We formulate and test hypotheses on a dataset collecting the publication records of the population of 4510 Italian academics in business and management and in architecture in the 2004-2013 period. Findings disclose that, alongside previous achievements, research-oriented settings favour research excellence. In addition, we show that a research-oriented context enhances the publication record of academics without highly ranked publications, whereas it slightly reduces the productivity of outstanding academics. Implications for public policy, especially in terms of performance measurement systems, are presented.
\end{abstract}

\section{KEYWORDS}

Research excellence; performance measurement; publications; university; higher education

\section{Introduction}

Research excellence has been the underlying logic of several higher education reforms across Europe in the last 20 years. Although different in their operational aspects, institutional actions share the assumption that excellence must become the main goal of universities as public institutions (Capano 2011; Frølich 2011; Lewis 2014; Degn 2016).

Attaining excellence in the university system is of the utmost importance because it fosters the success of academic institutions (Hallett 2010) and sustains national economic development (Krücken 2014; Fussy 2017). The achievement of this goal relies on the implementation of outputoriented management practices (Frølich 2011; Teelken 2015; Fussy 2017) or performance-based funding (Frølich 2011) in which explicit outcome indicators are periodically appraised and rewarded. According to this logic, academics are encouraged to pursue first and foremost excellence in research, while still providing valued teaching, being able to access competitive funding, and exerting a positive social influence on society (Bak and Kim 2015; Kok and McDonald 2017).

Defining research excellence in higher education is not straightforward, however, since its interpretation depends on the perspectives of various stakeholders (Tijssen 2003; Aguinis et al. 2014; Kok and McDonald 2017). A common, albeit vague, definition maintains that excellence in research be a publishing behaviour oriented towards both quality and quantity (O'Connor and 
O'Hagan 2016; Kok and McDonald 2017). From a stakeholder-based view, though, research excellence can be linked to the capability to address societal needs and interests, and provide impetus for collective advancement. In this sense, research excellence is intertwined with the concept of relevance or impact on a wider audience than the scientific community only (Aguinis et al. 2014; Maclntosh et al. 2017).

Awareness of the importance of research quality for social development and individual careers is not sufficient for its pursuit. Academics in fact enjoy a valued autonomy that leads them to choose their courses of action quite independently of institutional pressures (Knights and Clarke 2014; Degn 2016). Within the generally invoked autonomy, individual characteristics may affect the propensity to engage in research-oriented behaviours, such as previous performance and the capability to build a network of collaborative ties (Williamson and Cable 2003; Leahey 2006, 2007). Environmental features can create a setting favourable to research, too: for instance, the opportunity to cooperate with colleagues with heterogeneous background, gender, or position can affect the capacity to generate high-quality outcomes (Bland et al. 2005; Stewart 2006). Since the research process can be considered creative in nature (Shin and Zhou 2003; Stewart 2006), the relationship between individual and contextual factors is likely relevant in fostering research excellence, too, thus rendering the overall picture quite complex.

This study intends to contribute to the compelling comprehension of how individual and contextual features, as well as their interplay, promote research excellence.

The findings of a regression analysis run on 4510 academics show that individual factors do matter: previous focus on high-quality research and the nurturing of international collaborations exert more influence than contextual factors on publication outcomes. Nevertheless, a mixed setting enhances research excellence both directly and by leveraging individual features: less experienced academics in fact benefit from the interaction with colleagues with stronger publication records.

Our work expands on the debate on academic excellence, looking at the effects of the impulse towards research performance from a different perspective - the behaviours of academics who decide on their courses of action. By arguing that the introduction of a research-based performance measurement system should be carefully tailored on its recipients' characteristics, we advocate the importance of considering heterogeneous contexts, namely the composition of research groups in terms of their members' past achievements. Appropriate policies should therefore take into account not just individual stimuli to achieve better results, but also contextual features to promote favourable work environments for academics.

\section{Theoretical framework}

Social values have been emerging as the drivers of public domain management (Bozeman 2007; Wright 2007). The importance of public service values can be traced back to their being 'the subset of social, professional, ethical, and other values that are related directly to a person's role as a public servant, and would be acknowledged by that public servant as reasonable, legitimate, and relevant in carrying out the functions of a given position in the public sector' (Witesman and Walters 2014, 377). Values provide normative consensus about the fundamental principles of governance and policies, and undergird behaviours and the explanation of their occurrence (Witesman and Walters 2014). Notably, values and actions are necessarily intertwined, so that the actual potency of values can be better grasped through the actions implemented than through formal declarations (Nag, Corley, and Gioia 2007).

Higher education systems have gradually embraced transparency and accountability as core values over the past decades (Brew and Lucas 2009; Capano 2011; Frølich 2011; Lewis 2014). The need to reinforce these social values is rooted, on one hand, in the intention to improve the competencies of both academics and administrative staff to sustain economic development, and, on the other hand, in the necessity to allocate fewer resources because of the revision of the Welfare 
State's financial assets (Capano 2011). Their adoption is related to the implementation of outputoriented management practices (Van Dooren and Van de Walle 2008; Teelken 2015; Overman, Akkerman, and Torenvlied 2016) in which explicit outcome indicators are assessed and rewarded. Regarding academics specifically, accountability and transparency have been traced back to a mantra - attaining excellence in research - to be kept carefully in mind (Capano 2011; Bak and Kim 2015).

Placing emphasis on research is neither a straightforward effort nor is it devoid of hurdles. First of all, agreeing on the meaning of excellence remains complex. Although it is most commonly interpreted as the publication performance, measured by the number of (top) articles published, the number of citations, or the $\mathrm{h}$-index, that a person achieves in a given time span, therefore addressing a scientific debate, the idea that outstanding research should also be impactful for the larger society has been increasingly voiced (Butler, Delaney, and Spoelstra 2015; Maclntosh et al. 2017). A wider view on excellence resonates with the multi-stakeholder perspective of universities, according to which research products must serve a variety of actors, ranging from the scientific community to students, from public institutions to firms (Aguinis et al. 2014). This connotation is well documented in the British Research Excellence Framework (REF), which requires that meaningful case studies be submitted for evaluation by departments in addition to publications (Martin 2011). Heterogeneous understandings can be provided also by individuals who belong to the one and the same institution. For instance, O'Connor and O'Hagan (2016) report on variations among academics of the same university in the definition of excellence and in the implementation of the related evaluation practices.

In addition, a few studies have delved into the detrimental effect that the introduction of managerial principles expressing the sought-after values might have on academics' motivation, prompting a shift from self-control to external control (Overman, Akkerman, and Torenvlied 2016). The values sponsored deeply touch upon professional identity, i.e. the response to the question 'Who are we as academics?', and engender reactions to identity threats that vary from compliance and a shift towards productive research subjects to denial and focus on preferred activities and themes (Degn 2016; Huang, Pang, and Yu 2016). Since the academic profession has been traditionally endowed with the autonomy ensuing from expert knowledge (Capano 2011; Frølich 2011), many academics have been experiencing a contradiction between professionalism and managerialism (Lewis 2014; Denis, Ferlie, and Van Gestel 2015; Teelken 2015). This conflict, also labelled as hybridity, implies a tension between the independence of choice that specialised knowledge fosters and the necessity to comply with hierarchical control and rules that the search for excellence has introduced (Lewis 2014; Teelken 2015).

An interesting perspective on research excellence and autonomy holds that, although academics are well aware of the pressure to publish, they often react by developing resistance tactics, such as pursuing their own lines of inquiry, that reflect their inner beliefs in academia, but may marginalise them within their close research setting (Davies, Gottsche, and Bansel 2006; Clegg 2008; Nickson 2014; Cheng 2017). Nickson (2014) and Cheng (2017) also question the specific practices that single universities implement to sustain the search for excellence, since some grant academics greater margins of freedom in deciding what topics to investigate and with what methodologies.

As a consequence, research testifies to heterogeneous publishing behaviours following the statement of values. An empirical study by Frølich (2011) reports that the Norwegian reform has only slightly affected publication patterns of academics, with $90 \%$ of interviewees declaring that they have not modified their publishing practices to meet the expected requirements. Relatedly, Teelken (2015) accounts for the three-step process that leads some academics to change their publishing behaviours as a consequence of the new stimuli received: after a first stage in which academics develop a stronger awareness about the possible outcomes of their research, they go through a second phase in which they place emphasis on assessment criteria and on the related incentives and sanctions, to end up with finally regaining control over the content of their research. If it is indisputable that academics are 'not simply passive recipients of top-down public reform; rather, they shape its enactment at the local level' (Frølich 2011, 844), it is of a paramount importance 
to realise what factors affect the adoption of publishing behaviours that are in line with the research excellence desired of higher education public servants.

To date, we are aware that academics interpret and react differently against institutional requirements, but we have only a limited understanding of the mechanisms that orient them towards valuecongruent behaviours, which this paper intends to expand on. Research has polarised into individual or contextual characteristics, with the former receiving greater attention than the latter (Crane 1965; Park and Gordon 1996; Long et al. 1998; Acuna, Allesina, and Kording 2012).

The embracement of excellence and the consequent enactment of congruent behaviours has been traced back to the compatibility between social and personal values (Posner and Schmidt 1993; Wright 2007; Van Der Wal, De Graaf, and Lasthuizen 2008). Social values are weighed, evaluated and ultimately selected as justifications for action at an individual level based on personal value systems and preferences (Witesman and Walters 2014).

Conversely, other studies attribute the adoption of behaviours congruent with social values to the features of the environment in which the individuals act and interact. Specifically, the characteristics of the university to which an academic belongs turn out to be more influential than individual-level characteristics (e.g. Lerner and Tetlock 1999; Lewis 2013). In her study conducted in three universities located in Australia, Great Britain and New Zealand, Lewis (2014) argues that differences between universities outweigh individual factors such as disciplinary, seniority or gender differences, and that an institutional effect is at play in accounting for academics' publication choices following a reform.

Organisational behaviour literature can offer a useful reference for framing the influence of various factors on decisions and actions, telling us that human behaviour in the workplace is rarely the outcome of a solitary effort nor is it produced by institutional forces alone (e.g. George and Jones 2012): it is rather the product of the interplay between individual peculiarities on one hand, and contextual factors on the other hand. Vogelgesang, Denson, and Jayakumar (2010) support this argument for higher education, calling for more reflection on the intertwining of variables that promote or hamper the quality of the research. Accordingly, the research question of this study is: What are the joint effects of individual and contextual factors on research excellence?

\section{Hypotheses}

To test the above research question, we formulate hypotheses that take into account individual and contextual factors, and their interplay, by drawing from studies on academic productivity (Crane 1965; Park and Gordon 1996; Long et al. 1998; Acuna, Allesina, and Kording 2012) and on organisational behaviour, especially work groups (Guzzo and Dickson 1996; Stewart 2006).

\section{Individual factors}

\section{Individual quality}

According to behavioural consistency theory (Wernimont and Campbell 1968), the best predictor of a future job behaviour is the past behaviour in the same task. Completing a task successfully increases the level of skills and enhances knowledge of the process: for instance, individuals able to publish before the end of their PhD programme are expected to be more productive than individuals with no pre-PhD publications (Park and Gordon 1996). For this reason, past productivity has been considered an important estimator of future research excellence (Williamson and Cable 2003). Since the number of past publications tends to overlook the quality of work as an important dimension of research excellence, most university systems target the number of papers published in prestigious journals (Groot and García-Valderrama 2006; Horta, Dautel, and Veloso 2012; Leišytė 2016). Given the relevance of both quantity and quality of past performance in explaining variation in research excellence, we propose that:

Hypothesis 1: Past research excellence positively influences future research excellence. 


\section{Focus on non-mainstream research}

A well-known motivation for academics to publish is to share research results with the scientific community (Merton 1973), and recent research has shown that publishing in non-mainstream journals could have profound reasons not uniquely related to a lack of training to target highly ranked journals. Chavarro, Tang, and Ràfols (2017) point out that this practice could be fostered by a knowledge-bridging aim, i.e. bringing diverse communities closer to mainstream journals, or could be oriented at proposing research outcomes on topics not covered by mainstream journals (knowledge gap-filling). While several national agencies base their evaluations systems upon journal rankings, a large number of researchers still focus on knowledge-bridging and knowledge gap-filling activities addressing non-ranked journals, book chapters and conference proceedings. This behaviour resonates with the professional autonomy that pertains to academics recalled above. Besides qualitative findings that show how publishing in non-mainstream journals may help train researchers to publish in mainstream journals (Chavarro, Tang, and Ràfols 2017), recent quantitative evidence has highlighted that tenure decisions can be positively influenced not just by refereed journal articles, but also by book writing, whereas chapters have only a limited effect, and other types of publications may even be detrimental (Lutter and Schröder 2016). Conversely, specialisation in writing for top journals may help scientists master a literature domain in depth and be recognised as experts in the field by peers, who often participate in the publication process as editors and reviewers. Consequently, according to this perspective, high-quality research productivity is promoted and enhanced by specialisation (Leahey 2006, 2007). Although targeting diverse types of outlets such as books, chapters and conference proceedings may be driven by knowledge-driven rationales, a diversified focus can hinder the chance of achieving research excellence, as we posit below:

Hypothesis 2: A past focus on non-mainstream research negatively impacts on future research excellence.

\section{International collaborations}

Scientific collaboration exerts a prominent role in accounting for differences in research excellence (Zuckerman 1967; S. Lee and Bozeman 2005). Cooperation fosters the flow of knowledge within and across scientific communities (Adams et al. 2005), and its positive effects on scientific productivity have been tested at an individual (S. Lee and Bozeman 2005), group (Van Raan 1998; Barjak and Robinson 2008), as well as at more aggregated levels of analysis (Abramo, D'Angelo, and Di Costa 2009). Policy makers have then started supporting collaboration practices in academia (S. Lee and Bozeman 2005; European Commission 2008). Collaboration may take on different forms, but despite the wide range of possibilities that researchers can avail themselves of, such as student exchange, visiting scholarship, common research projects, and informal conversations at conferences, scholars have focused mainly on the co-authorship of scientific papers because it represents clear evidence of cooperation (Van Raan 1998; Abramo, D'Angelo, and Di Costa 2009). Along this line of reasoning, studies on the relationship between collaboration and research productivity have increasingly delved into the effect of international collaboration, since the globalised nature of science imposes to broaden the horizon of ties (Van Raan 1998; Barjak and Robinson 2008; Abramo, D'Angelo, and Di Costa 2009). Empirical evidence has shown contrasting effects, however, with a slight prevalence of the positive impact of international collaboration: research cooperation is positively related to scientific productivity (Van Raan 1998; Barjak and Robinson 2008), but its influence varies according to the field considered (Abramo, D'Angelo, and Di Costa 2009) and to the way productivity is gauged (Adams et al. 2005). The mixture of positive and negative effects calls for further investigation and leads us to formulate the following hypothesis: 


\section{Contextual factors}

\section{Research context quality}

Not only individual characteristics, but also context characteristics have a relevant influence on research excellence (Crane 1965; Fox 1983; Long et al. 1998). According to social learning theory, people learn from peers by observing, imitating and modelling their behaviours (Bandura 1962). Working in a department populated by researchers able to publish in highly ranked journals can constitute a precious learning opportunity for scholars. For example, Braxton (1983) identifies a positive correlation between the publication rate of department colleagues and individual productivity. Qualified academics can provide colleagues with valuable feedback and suggestions about the publication process, nourishing discussion and the sharing of ideas (Parker and Lingwood 1968). Excellent scholars in fact maintain frequent contacts with peers aimed at investigating professional issues (Pelz and Andrews 1976). Finally, the social influence exerted by a context characterised by high-quality standards can stimulate scholars to improve their research quality to align themselves with their colleagues (Salancik and Pfeffer 1978). Thus, we propose the following hypothesis:

Hypothesis 4a: The presence of colleagues with past research excellence in the same department positively impacts upon future research excellence.

Although stimulating contexts are expected to positively influence academics' productivity, the effects of the quality of the working environment on individual outcomes seem to be complex and call for further elucidation (Crane 1965; Braxton 1983; Fox 1983; Creswell 1985; Long et al. 1998). Working in a context with scarce emphasis on research and low research quality negatively affects research productivity (Bland and Ruffin 1992; Bland et al. 2005) so that departments without clearly stated research goals and programmes attain lower research performance (Baird 1986). To account for a detrimental influence of the work setting on publication outcomes, we therefore include in our set of hypotheses the influence of colleagues with limited previous research excellence. Thus, we propose:

Hypothesis $4 \mathrm{~b}$ : The presence of colleagues without past research excellence in the same department negatively affects future research excellence.

\section{Heterogeneity}

Context heterogeneity has been long regarded as an important factor sustaining creative performance like the realisation of a paper for a highly ranked journal, whose first objective is the very provision of innovative contributions. Literature on groups has extensively delved into team composition as a driver of performance, distinguishing between demographic characteristics, such as age or gender, and deep-level characteristics, such as personality traits or values (e.g. Hansen and Levine 2009; Somech and Drach-Zahavy 2013). Heterogeneity may foster creativity processes leading to successful outcomes since it implies a variety of skills and experiences to be combined to solve complex problems (Stewart 2006). The effect of heterogeneity remains controversial, however. Some studies have posited that heterogeneity of job-related characteristics like competencies and past experiences be particularly influential (Webber and Donahue 2001). Research has also claimed that heterogeneity is especially salient in teams engaged in creative tasks, such as R\&D teams or groups of academics doing high-quality research in a discipline, but less relevant for teams performing routine tasks, such as a production unit (Guzzo and Dickson 1996; Stewart 2006). Since top publications differentiate from lower-level outcomes because of their innovative content, and therefore academics who attain this achievement have undertaken a creative process, we expect heterogeneity to positively impact upon research excellence and formulate the following hypothesis: 


\section{The moderating effect of the research context quality}

Publishing in top journals can be likened to innovation implementation: the idea of a research project is developed, discussed and refined until its outcome is deemed as being valuable enough to appear in a prestigious outlet. Studies on creativity and innovation can shed light on the role of the context in the process that goes from the elaboration of an original idea to its implementation into a product and/or a service (e.g. Madjar, Oldham, and Pratt 2002; Shin and Zhou 2003). The realisation of good ideas requires more than individual knowledge and skills and creative personalities: a favourable climate is necessary to see ideas through the different and effortful stages that lead to their successful accomplishment (Stewart 2006). Transferring this evidence to academic settings, the quality of an individual's prior publication pattern and network of relationships can be the starting point for generating new ideas and undertaking the related research. A high-quality setting in which outstanding researchers interact, though, increases the opportunities for ideas to be confronted, enriched and turned into excellent publications. Accordingly, we posit the following moderation effect of the quality of the research context between individuals' prior and subsequent research excellence:

Hypothesis 6: The research context quality moderates the relationship between past research excellence and future research excellence, such that the effect of past research excellence on future research excellence is reinforced when research context quality is high.

\section{Data and methods}

In this paper, we adopted a deductive approach focused on testing the hypotheses formulated in the theoretical framework. In doing so, we adhered to a post-positivistic paradigm, which begets the assumption that theoretical dimensions be directly studied through appropriate measures (Heppner and Heppner 2004; Bryman and Bell 2011, 21). Accordingly, in the next sections we used established measures to enhance the replicability of findings (Pugh et al. 1968).

\section{Data collection}

We tested our hypotheses on a large dataset regarding the publication outlets of the whole population of Italian academics in the fields of business and management and of architecture. Italy represents an interesting case for studying the effects of policy making, as a new reform, named 'Riforma Gelmini', was introduced in $\mathbf{2 0 1 0}$ that reshaped the evaluation system of Italian universities. The funding of universities was linked to research excellence measured as the number of publications presented by each university and evaluated by panels of experts, similar to what happens for the British REF (Rebora and Turri 2013).

The reform intent was to promote excellence by linking funding to the quality of research outcomes, although several of its aspects are considered controversial and have generated vibrant debates in the academic community (Cartlidge 2010). The National Agency for the Evaluation of the University System and of Research (ANVUR) was established and several disciplinary committees were in charge of defining evaluation criteria for the various areas (Daraio and Moed 2011).

The reform devises the use of bibliometric indexes for Life and Hard Sciences, while for Social Sciences and Humanities panels of experts produce lists of high-quality journals, named A-rated journals, relevant for their specific field (Bonaccorsi et al. 2017). The Italian A-rated journal lists do not assign an intrinsic quality to journals, as happens for the Chartered Association of Business Schools star ranking, but it is a plain list elaborated by combining several international ranking indexes. For instance, in the business and management field, the Association of Business Schools' Academic Journal Guide, the Impact Factor and the Scimago Journal Ranking were employed.

We focused on two non-bibliometric fields: architecture and business and management, because they both comprise two large populations of academics, but have considerable differences in the time lag going from submission to publication of papers. In business and management, the delay 
is about 18 months, almost twice as long as in architecture (Björk and Solomon 2013), thus impacting academics' careers in terms of tenure and grant application (Powell 2016). Our dataset was based on the data collected by ANVUR in two different rounds of evaluation: a first database collected all the outputs published between 2011 and 2013; a second database gathered the three best publications declared by each academic for the first evaluation exercise concerning the 2004-2010 period (Goglio and Parigi 2016).

We matched academics of the two databases, thus obtaining a population of 4510 active individuals in the whole period 2004-2013 (2926 in business and management and 1584 in architecture). We analysed their outputs to discover how their research profile and the features of their research settings in the 2004-2010 period influenced the quality of their outputs, i.e. their research excellence, in the subsequent 2011-2013 period.

\section{Measures}

To test the set of hypotheses of the previous section, we elaborated the following variables.

\section{Future research excellence}

As argued in the theoretical framework, research excellence is a multifaceted concept that can be operationalised in various ways (Tijssen 2003). Some authors maintain that the number of citations or a measure like the $\mathrm{h}$-index be best able to assess research excellence (e.g. Tijssen, Visser, and van Leeuwen 2002). Several studies on higher education reforms, though, focus on the number of top publications as a more direct measure of research excellence (Groot and García-Valderrama 2006; Horta, Dautel, and Veloso 2012). Coherently, we gauged research excellence - the dependent variable of our study - in terms of number of publications ('A-rated publications 2011-2013') in highly ranked journals per single academic in the 2011-2013 period, using the lists provided by the Agency (Bonaccorsi et al. 2017).

\section{Past research excellence}

To assess the past research excellence of an academic, we resorted to previous highly ranking publications as a predictor of future research excellence (Park and Gordon 1996). The variable 'A-rated publications 2004-2010' counted how many of the three research outputs declared by each academic for the 2004-2010 period were published in A-rated journals.

\section{Focus on non-mainstream research}

To appraise the commitment to publishing in non-ranked journals or in other outlets (Leahey 2006), we elaborated two measures. The variable 'other papers' is the number of papers submitted by each academic for evaluation in the 2004-2010 period, which were published in non-A-rated journals. The variable 'other contributions' refers to the number of publications different from papers declared by each academic in the same period (books, book chapters, conference proceedings).

\section{International collaborations}

Echoing Abramo, D'Angelo, and Di Costa (2009), we defined the variable 'Collaborations with international co-authors' as the count of research outputs (papers, books, chapters or proceedings) made by a single academic with co-authors affiliated with a foreign university in the 2004-2010 period.

\section{Presence of colleagues with and without past research excellence}

The quality of the research context was measured by the number of academics in the department who belong to the same discipline and who produced at least one paper in an A-rated journal in the 2004-2010 period ('Peers with A-rated pubs'). Within a discipline, in fact, scholars express a combination of similar and dissimilar characteristics in terms of orientation, strategies or source of motivation, which has been found to be positively related to scientific performance (Pelz and Andrews 
1976). Conversely, we have calculated the presence of colleagues without past research excellence as the number of colleagues of the department in the same discipline who did not have any publications in an A-rated journal in that time span (Peers without A-rated pubs). Altogether, these two variables account for the quality of the research context: a high-quality setting encompasses many peers with past research excellence and few peers without past research excellence, whereas an opposite combination implies low quality of the research context.

\section{Heterogeneity}

In order for heterogeneity in terms of categorical attributes such as gender and position to be appraised, both Blau's and Teachman's indexes are considered appropriate (Harrison and Klein 2007), with the former being preferable because of its easier calculation procedure and more intuitive and compelling probabilistic interpretation (Budescu and Budescu 2012). An index for position was calculated as $1-\sum P_{\mathrm{i}}^{2}$, where $P_{\mathrm{i}}$ is the proportion of the total number of colleagues holding the same role (temporary assistant professor, permanent assistant professor, associate professor and full professor). After calculating the index for gender through the same procedure, the overall Blau's index sums up the two measures for position and gender (Hmieleski and Ensley 2007). Thus, the scores for the final index range from 0 (completely homogenous) to 2 (completely heterogeneous).

\section{Control variables}

The literature has extensively addressed gender gaps in research and academic productivity (Cole and Zuckerman 1984; J. S. Long and Fox 1995; Xie and Shauman 1998; Leahey 2006). The studies devoted to account for gender differences in publishing have led to the identification of several characteristics, such as role and facilitating resources, that may explain the higher research productivity of male academics (Xie and Shauman 1998), but there is still no consensus on the reasons why men and women differ systematically in these important dimensions. Thus, we included gender, role and a dummy variable to differentiate between academics in business and management and academics in architecture as control variables. Moreover, we added the university size as a categorical variable based on a report produced by the Statistical Office of the Italian Ministry of Education, University and Research (Ministero dell'Istruzione dell'Universitá e della Ricerca - Ufficio di Statistica 2014). Large universities are in fact likely to outperform small universities in terms of the quality and quantity of inputs offered to the research process (Beyer, Chanove, and Fox 1995). University size takes into account the number of students enrolled in all programmes in the 2012-2013 academic year to define three classes: 1 for universities with fewer than 10,000 students, 2 for universities with a number of students between 10,000 and 20,000 and 3 for universities with more than 20,000 students. Table 1 summarises the variables considered in the study and shows their correlations. In the 2011-2013 period, the number of A-rated publications has risen to 0.808 per person (it was equal to 0.439 in the previous time span considered), but still remains quite low. Furthermore, the average number of peers in the same department and discipline with excellent publications is considerably lower (2.827) than the average number of colleagues without any A-rated publications (6.960).

\section{Method of analysis}

Since the dependent variable is the count of publications per academic, it is not normally distributed and positively skewed, with large values being rare. A Poisson regression is not appropriate because it imposes the constraint of the equality of mean and variance, which does not hold for our data, while it is advisable to adopt a negative binomial regression (J. S. Long 1997; Horta, Dautel, and Veloso 2012; S. J. Lee and Jung 2017). We contrasted the Poisson and the negative binomial model with the likelihood-ratio test for the overdispersion coefficient (alpha), reporting a significant coefficient that confirms an improvement of fit with the negative binomial model. The first model combines individual and contextual factors, while the second model includes the moderation effect. We used 
Table 1. Descriptive statistics of the numerical variables of the study: means, standard deviations, minimum and maximum values, Pearson correlation coefficients and their significance.

\begin{tabular}{|c|c|c|c|c|c|c|c|c|c|c|c|}
\hline & Mean & SD & Min & Max & $\begin{array}{l}\text { A-rated publications } \\
2011-2013\end{array}$ & $\begin{array}{l}\text { Previous A-rated } \\
\text { publications 2004- } \\
2010\end{array}$ & $\begin{array}{l}\text { Other } \\
\text { papers }\end{array}$ & $\begin{array}{c}\text { Other } \\
\text { contributions }\end{array}$ & $\begin{array}{l}\text { Collaborations with } \\
\text { int. co-authors }\end{array}$ & $\begin{array}{l}\text { Peers with A- } \\
\text { rated pubs }\end{array}$ & $\begin{array}{l}\text { Peers without } \\
\text { A-rated pubs }\end{array}$ \\
\hline $\begin{array}{l}\text { A-rated publications } \\
2011-2013\end{array}$ & 0.808 & 1.785 & 0 & 32 & 1 & & & & & & \\
\hline $\begin{array}{l}\text { Previous A-rated } \\
\text { publications 2004- } \\
2010\end{array}$ & 0.439 & 0.809 & 0 & 3 & $0.34^{* *}$ & 1 & & & & & \\
\hline Other papers & 0.763 & 0.914 & 0 & 3 & $-0.05^{* *}$ & $-0.14^{* *}$ & 1 & & & & \\
\hline Other contributions & 1.455 & 1.160 & 0 & 3 & $-0.22^{* *}$ & $-0.51^{* *}$ & $-0.57^{* *}$ & 1 & & & \\
\hline $\begin{array}{l}\text { Collaborations with int. } \\
\text { co-authors }\end{array}$ & 0.233 & 0.608 & 0 & 3 & $0.18^{* *}$ & $0.37^{* *}$ & $0.04^{* *}$ & $-0.24^{* *}$ & 1 & & \\
\hline Peers with A-rated pubs. & 2.827 & 4.885 & 0 & 35 & $0.19^{* *}$ & $0.38^{* *}$ & 0.00 & $-0.26^{* *}$ & $0.19^{* *}$ & 1 & \\
\hline $\begin{array}{l}\text { Peers without A-rated } \\
\text { pubs. }\end{array}$ & 6.960 & 8.322 & 0 & 59 & $-0.05^{* *}$ & $-0.17^{* *}$ & $-0.13^{* *}$ & $0.19 * *$ & $-0.09^{* *}$ & $0.21^{* *}$ & 1 \\
\hline Blau's index & 1.177 & 0.542 & 0 & 1.96 & 0.01 & -0.03 & -0.02 & $0.04^{* *}$ & $-0.03^{*}$ & $0.24^{* *}$ & $0.38^{* *}$ \\
\hline
\end{tabular}

** $p<01$;

${ }^{*} p<.05$

${ }^{+} p<.1$. 
robust estimators to control for mild violation of underlying assumptions, as suggested by Cameron and Trivedi (2013).

\section{Results}

The results of the two regression models are presented in Table 2, with the related fit parameters.

Model 1 tested individual and contextual hypotheses. Model 2 included the interaction term between 'Past research excellence' and 'Presence of colleagues with past research excellence' to test Hypothesis 6 . As a reference group for the categorical control variables, we chose female academics in the architecture field with the role of temporary researchers. For each model, we reported on the exponential coefficient, the $p$-values and the standard error. Coefficients are incidence rate ratios: in other words, they show how many times the dependent variable would increase for one unit of change in the dependent variable.

Our findings supported Hypothesis 1 on the effect of previous performance on future performance: having been excellent in research between 2004 and 2010 had a positive effect on the research excellence in the subsequent 2011-2013 period. An additional publication in an A-rated journal increased in fact the predicted outcome by 1.534 times.

Conversely, we found a partial support for Hypothesis 2 about focus on non-mainstream research: having published papers in a low-ranking journal, in our case a non-A-rated journal, did not have a significant effect on future publication performance, while having spread research efforts in various outlets (books, chapters and conference proceedings) had a negative effect on publications in Arated journals. An incremental publication in an outlet different from top journals reduced by $34.4 \%$ the expected number of A-rated publications. Although our findings do not allow us to state that a broader focus on dissemination to include lower-ranked journals is detrimental to research excellence, we disclose that targeting a diversified set of outlets does reduce the possibility of attaining research excellence.

Table 2. Negative binomial regression results for research excellence.

\begin{tabular}{|c|c|c|c|c|}
\hline \multirow{2}{*}{ Variables } & \multicolumn{2}{|c|}{ Model 1} & \multicolumn{2}{|c|}{ Model 2} \\
\hline & Exp. Coef. & Robust SE & Exp. Coef. & Robust SE \\
\hline A-rated publications 2011-2013 (dependent variable) & & & & 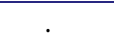 \\
\hline Gender $(0=$ female, $1=$ male $)$ & $1.142^{*}$ & 0.072 & $1.147^{*}$ & 0.072 \\
\hline Field $(0=$ Architecture, $1=$ Business and Management field $)$ & $0.293^{* *}$ & 0.031 & $0.299^{* *}$ & 0.033 \\
\hline Permanent researcher & $0.706^{*}$ & 0.114 & $0.710^{*}$ & 0.113 \\
\hline Associate professor & $0.677^{*}$ & 0.120 & $0.688^{*}$ & 0.122 \\
\hline Full professor & $0.750^{+}$ & 0.130 & 0.758 & 0.130 \\
\hline Medium university & $1.352^{* *}$ & 0.158 & $1.344^{*}$ & 0.160 \\
\hline Large university & $1.371^{* *}$ & 0.133 & $1.361^{* *}$ & 0.134 \\
\hline Previous A-rated publications 2004-2010 & $1.534^{* *}$ & 0.097 & $1.701^{* *}$ & 0.115 \\
\hline Other papers & 0.965 & 0.059 & 0.962 & 0.060 \\
\hline Other contributions & $0.656^{* *}$ & 0.043 & $0.669^{* *}$ & 0.045 \\
\hline Collaborations with int. co-authors & $1.255^{* *}$ & 0.049 & $1.252^{* *}$ & 0.048 \\
\hline Peers with A-rated pubs. & $1.028^{* *}$ & 0.005 & $1.061^{* *}$ & 0.009 \\
\hline Peers without A-rated pubs. & $0.980^{* *}$ & 0.005 & $0.978^{* *}$ & 0.005 \\
\hline Blau's index & $1.157^{*}$ & 0.079 & $1.153^{*}$ & 0.080 \\
\hline Previous A-rated publications $2004-2010 \times$ Peers with A-rated pubs. & & & $0.976^{* *}$ & 0.005 \\
\hline Constant & $1.676^{*}$ & 0.362 & $1.507^{+}$ & 0.330 \\
\hline $\ln ($ alpha) & $0.414^{+}$ & & $0.399^{+}$ & \\
\hline Observations & 4510 & & 4510 & \\
\hline Wald $x^{2}$ & $\begin{array}{r}1074.27 \\
(14 d f)\end{array}$ & & $\begin{array}{c}1095.69 \\
(15 d f)\end{array}$ & \\
\hline Prob. $>x^{2}$ & 0.000 & & 0.000 & \\
\hline Log-likelihood & -4939.019 & & -4927.871 & \\
\hline
\end{tabular}

**p $p<.01$

${ }^{*} p<.05$

${ }^{+} p<.1$. 
The analysis supported Hypothesis 3 on the influence of international collaboration: an additional international collaboration increased the expected number of A-rated papers by $25.5 \%$.

The quality of the research setting was addressed by Hypotheses $4 \mathrm{a}$ and $4 \mathrm{~b}$. Our results showed that being part of a context with colleagues who are excellent in research can improve an academic's own future research excellence (Hypothesis $4 a$ ): adding a colleague with an A-rated publication can in fact increase individual research performance by $2.8 \%$. Since the percentage of those who published in A-rated journals was low (only $18.7 \%$ in business and management and $31.5 \%$ in architecture, respectively), stimulating colleagues to publish in A-rated journals becomes mandatory to attain excellence. If just five additional peers in a department disciplinary group published in A-rated journals, the expected number of individual publications would rise by $14 \%$ on average. A possibility for improving research excellence then might be to raise the number of peers studying the same discipline through the hiring of new colleagues. Nevertheless, Hypothesis $4 \mathrm{~b}$ showed that an additional colleague without past research excellence reduced the expected outcomes by $2 \%$. In other words, hiring academics without a past track record of research excellence negatively affects the individual performance of colleagues.

Our results did not confute Hypothesis 5 about heterogeneity, showing that academics in research settings with mixed gender and positions are more likely to produce excellent publications. For instance, a high Blau's index of 1.5 can be reached through different combinations of gender and position: considering the current gender distribution (61.78\% of males) emerging from our data, there should be fewer than $34.4 \%$ of academics holding the same position among the members of the same discipline in the same department.

We tested the moderation hypothesis of the research context quality on the effect of individual previous research performance in Model 2. Surprisingly, our findings unravelled a significant moderation effect partially different from the relationship formulated in Hypothesis 6 . As posited, our results testified to a moderation effect of the research context, so that academics with fewer publications benefited from favourable contexts in achieving research excellence. Nevertheless, our findings showed that academics who were already outstanding researchers received decreasing benefits from the improvement of the research context, while we would have expected just a simple reduction of the context effect in their case. In other words, an improvement of the quality of the context appeared to have slightly detrimental effects on top academics.

This articulated moderation effect is reported in Figure 1: each line represents the expected production of academics with a record of respectively $0,1,2$ or 3 A-rated publications in the first evaluation round. The $x$-axis shows the number of academics in a given research setting holding at least an A-rated publication.

Academics with previous limited research performance (past A-rated publications $=0$ or 1 ) turned out to be strongly influenced by their research context: if they worked in an environment with few peers with at least one A-rated publication in the previous evaluation round, they did not produce high-quality research outputs in the subsequent one. They likely struggled to find support, advice and guidance towards the attainment of excellent research goals. Conversely, when less performing academics operated in a favourable context, they were driven towards high-quality publishing. When there were more than 15 colleagues with A-rated publications in the same field, the expected value of the dependent variable was approximately 1 , meaning that a less performing academic in the previous evaluation round would carry out at least a top publication in the new round. The effect of moderation disappeared when there were between 20 and 25 academics with an A-rated publication who studied the same discipline in a department. This dimension was far from the average one in the 2004-2010 period, though, which amounted to 2.8. In order to mobilise the large base of 3257 academics without any A-rated publications, an increase in the number of colleagues who have already achieved excellence targets is needed. This might be easier to do in the business and management field because research groups within departments are on average larger than in architecture (8.4 members in the latter versus 12.3 members in the former). 


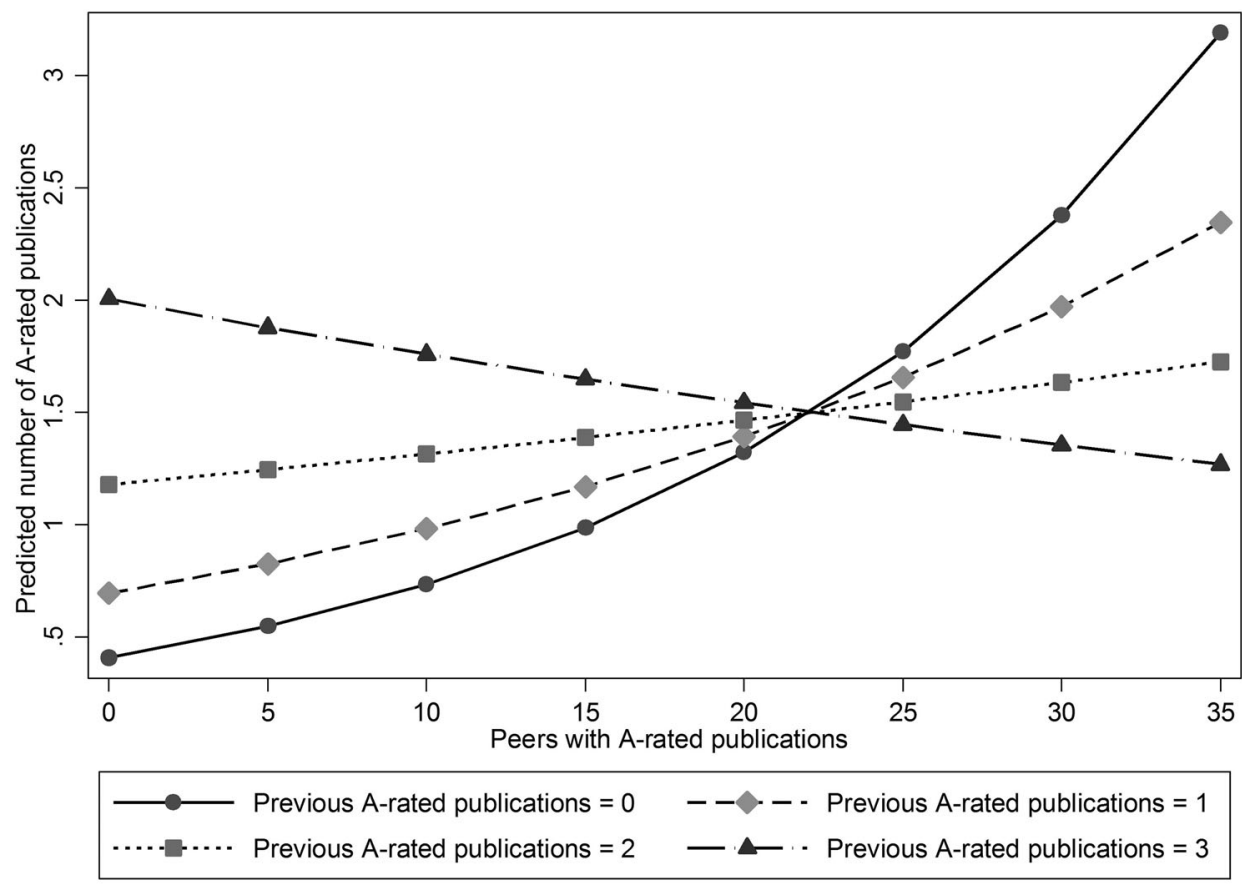

Figure 1. The moderation effect of the research environment quality on the relationship between past and future research excellence.

A final remark addresses academics who were already excellent in the 2004-2010 evaluation round ( 2 or 3 previous A-rated publications): their productivity was less affected by the introduction of outstanding peers in the same discipline and department than it was by colleagues who did not perform well. A possible explanation for this evidence is that excellent researchers already possess the skills to carry out high-quality publications and therefore do not benefit from opportunities to interact with other outstanding researchers as much as less performing colleagues do. This interpretation seems particularly plausible for academics who presented 3 A-rated publications in the 20042010 evaluation round: when the number of outstanding colleagues operating in the same discipline and department increased, their individual productivity decreased slightly. We will discuss this outcome in the next section.

Concerning control variables, coherently with similar studies (e.g. Horta, Dautel, and Veloso 2012), males turned out to be more productive than females (14.2\%), while being in business and management reduced A-rated publications by more than $70 \%$. Finally, our results showed that career progression negatively affected future research excellence: permanent researchers, associate and full professors were less productive than temporary researchers, in line with a consolidated view on the topic (Xie and Shauman 1998; Fabel 2008).

\section{Discussion}

Our work investigated the effects of individual and contextual factors, as well as their interplay, on the attainment of research excellence in the higher education sector. Research excellence has become, over the past decades, the most representative expression of the transparency and accountability values that should underlie University systems (O'Connor and O'Hagan 2016; Kok and McDonald 2017). Overall, our results showed that individual features influenced research excellence, but that context also played a fundamental role. Individual factors like past research excellence and 
international collaborations were indicators of the ability to achieve research excellence again, while the spread of efforts in diversified outlets was detrimental. Contextual variables reinforced individual performance: if an academic works in an environment to which other excellent scholars are affiliated, a general research enhancement occurs, which is also sustained by the heterogeneity of the research setting. Conversely, if the work context is populated by academics with poor publication experiences, that would result in lower research standards. Finally, the quality of the research context moderated individual ability, in that an academic without a robust past research experience strongly benefited from a well-developed work setting that offered outstanding publication exposure. Academics with a significant publication background did find it fruitful to work in a context in which many other colleagues with similar experiences operated, though. All in all, while larger contexts might be considered beneficial for enhancing productivity, increasing the size of research settings did not emerge as being always convenient.

Comprehending the complex set of relationships undergirding research excellence enables us to realise that a clear statement of goals through a reform coupled with a performance measurement system (Frølich 2011; Teelken 2015) is not sufficient to sustain the embracement of congruent behaviours, and a reflection on how to actually achieve the aspired objective is required. We already know that individual characteristics, especially the consistency between personal and public values on the one hand (e.g. Witesman and Walters 2014), and environmental factors, such as the policies implemented by single universities (Lewis 2014) on the other hand, can influence behaviours and outcomes of civil servants. We enriched this knowledge by showing how the intertwining between researchers' past performance, international ties, peers' past performance and heterogeneity positively influences research excellence, and we unravel the moderating role played by peers' quality. Awareness of the interplay between individual and contextual factors can further the debate on hybridity (Lewis 2014; Teelken 2015) in academia: handling universities in an effective way is not about privileging autonomy versus managerialism, but rather about combining individual choices with organisational design.

Contextual factors appear to be the appropriate lever to further the adoption of desired behaviours and results, but our study sheds light on the contradictions that such intervention may encompass. Individual research may benefit from the presence, within the same department, of peers with a previous excellent performance track. Figure 1 discloses how an increase in the number of highquality peers within a setting actually betters the number of low performers' top publications: attracting top researchers into a department might therefore emerge as a successful strategy to align collective outcomes with expected performance. The reaction of excellent researchers against the infusion of peers with a similar profile that can be gleaned from our analysis brings to the fore a caveat, however: top performers do not benefit from the potential access to other excellent researchers, as the number of their A-rated publications slightly diminishes. This might be due to several reasons: in a context populated by excellent researchers, competition for scant resources, such as internal funding, is bound to get harder, alongside minor opportunities for differentiation in terms of time devoted to research as against teaching (Krücken 2014; Leišytė 2016). Another reason could be linked to the effort of transferring knowledge to less expert colleagues: that demanding activity may lessen attention towards one's own research. We believe that this finding conveys a relevant hint for public policy: university management should be aware that there is a relationship between an increase in low performers' and a decrease in top performers' research outcomes that needs to be addressed. The search for a more stimulating environment through the resort to brilliant researchers may penalise their very performance and prompt their subsequent decision to switch to a different setting, such as another university, in which to attain more satisfactory goals. European university systems have been consistently emphasising the relevance of excellence in research, although heterogeneous performance management systems have been designed in the different countries (e.g. Krücken 2014). The risk that top researchers' performance may decline over time, while - and maybe because - their less performing colleagues improve their own research quality, leads us to foster the necessity of revising indicators and incentives so as to value the contribution of researchers 
at an institutional level, and not at an individual level only, and therefore be able to retain outstanding scholars in the long run. National systems all rely on individual evaluation: it is individual productivity that is acknowledged and then summed up at the department and university level. Policy makers may consider, in addition to individual appraisal, introducing some sort of collective assessment to recognise and reward collaboration between top and low performers: it might be the case of A-rated publications co-authored by researchers with different publishing records. By doing so, a marginally decreasing performance by excellent researchers would be compensated by their support to enhance the productivity of less performing colleagues.

In general, we show that sponsoring behaviours in line with the desired outcome of excellence calls for flexibility in performance measurement to take into account the social dynamics that our study discloses. This is a particularly stimulating point in light of the consideration that university systems instead are rather oriented towards preserving a stability in individual evaluation measures.

\section{Limitations}

Our understanding of the mechanisms of interaction among excellent researchers is still not complete and future research could disclose what happens when new expert academics join a department, and specifically under what circumstances they compete or cooperate with peers already affiliated with the institution.

Additionally, although pursuing excellence in research has gradually taken centre stage, providing high-level teaching and impact on society are behaviours expected of academics, too. A growing body of research testifies to the conflict that researchers may experience in making decisions about what activities to privilege and what time to allocate to them (e.g. Vogelgesang, Denson, and Jayakumar 2010; Knights and Clarke 2014; Bak and Kim 2015; Leišytè 2016). Handling tasks of a different nature, ranging from teaching to institutional appointments, on a daily basis may represent the very situation in which hybridity between professionalism and managerialism is strongly felt by academics: they might come to see themselves as 'three-headed dogs', referring to the Greek mythological creature Cerberus, targeting simultaneously merit in research, teaching, and third mission, and puzzlement about the meaning of excellence emerges. Expanding on our comprehension of the drivers of academics' orientation towards research, teaching and impact on society can add much-needed clarity to the process of internalisation of social values following an institutional change.

Finally, replication of this study in different countries can further our comprehension of the interpretation of research excellence (Aguinis et al. 2014; O'Connor and O'Hagan 2016). While some higher education systems have implemented national reforms to sustain the social values of transparency and accountability that have marked a 'before' and an 'after', such as in Italy and Germany (Capano 2011), in others institutional shifts have occurred gradually over time, as in England and the United States. How academics interiorise and play out research excellence under different circumstances of exposure, and what outcomes may be generated, deserves elucidation.

\section{Conclusion}

With the introduction of university reforms, research excellence and related incentive systems have been officially promoted by public policies in European countries. The reactions of the population of academics have not been homogeneous: our results show that differences in performance can be justified by the combination of individual and contextual aspects. A 'one size fits all' policy and consequent incentive system may not be the best solution to promote research excellence, because they generate disparate outcomes that are not always in line with institutional expectations. Policy makers should therefore take into account heterogeneity in the initial situation and target different groups and contexts with appropriate interventions. 


\section{Acknowledgements}

We would like to acknowledge valuable comments by two anonymous reviewers. We are grateful to Dr Garcia-Garcia for her comments on the methodology. The usual disclaimer applies.

\section{Disclosure statement}

No potential conflict of interest was reported by the authors.

\section{Funding}

This work was supported by Italian National Agency for the Evaluation of the University System and of Research (ANVUR), UniPro project [grant number 00001757 04/09/2015]. ANVUR is not responsible for any analysis or elaboration presented in this paper.

\section{ORCID}

Giacomo Carli (iD http://orcid.org/0000-0001-9406-589X

Maria Rita Tagliaventi (D) http://orcid.org/0000-0002-3924-2029

Donato Cutolo iD http://orcid.org/0000-0003-2195-9870

\section{References}

Abramo, Giovanni, Ciriaco Andrea D'Angelo, and Flavia Di Costa. 2009. "Research Collaboration and Productivity: Is There Correlation?" Higher Education 57 (2): 155-71.

Acuna, Daniel E., Stefano Allesina, and Konrad P. Kording. 2012. "Predicting Scientific Success." Nature 489 (7415): $201-2$. Adams, James D., Grant C. Black, J. Roger Clemmons, and Paula E. Stephan. 2005. "Scientific Teams and Institutional Collaborations: Evidence from U.S. Universities, 1981-1999." Research Policy 34 (3): 259-85.

Aguinis, H., D. L. Shapiro, E. P. Antonacopoulou, and T. G. Cummings. 2014. "Scholarly Impact: A Pluralist Conceptualization." Academy of Management Learning \& Education 13 (4): 623-39.

Baird, Leonard L. 1986. "What Characterizes a Productive Research Department?" Research in Higher Education 25 (3): $211-$ 25.

Bak, Hee-Je, and Do Han Kim. 2015. "Too Much Emphasis on Research? An Empirical Examination of the Relationship Between Research and Teaching in Multitasking Environments." Research in Higher Education 56 (8): 843-60.

Bandura, Albert. 1962. "Social Learning Through Imitation." In Nebraska Symposium on Motivation, 211-72. Lincoln: University of Nebraska Press.

Barjak, Franz, and Simon Robinson. 2008. "International Collaboration, Mobility and Team Diversity in the Life Sciences: Impact on Research Performance." Social Geography 3 (1): 23-36.

Beyer, J. M., R. G. Chanove, and W. B. Fox. 1995. "The Review Process and the Fates of Manuscripts Submitted to AMJ." Academy of Management Journal 38 (5): 1219-60.

Björk, Bo-Christer, and David Solomon. 2013. "The Publishing Delay in Scholarly Peer-reviewed Journals." Journal of Informetrics 7 (4): 914-23.

Bland, Carole J., Bruce A. Center, Deborah A. Finstad, Kelly R. Risbey, and Justin G. Staples. 2005. "A Theoretical, Practical, Predictive Model of Faculty and Department Research Productivity." Academic Medicine 80 (3): 225-37.

Bland, Carole J., and Mack T. Ruffin. 1992. "Characteristics of a Productive Research Environment." Academic Medicine 67 (6): 385-97.

Bonaccorsi, Andrea, Cinzia Daraio, Stefano Fantoni, Viola Folli, Marco Leonetti, and Giancarlo Ruocco. 2017. “Do Social Sciences and Humanities Behave Like Life and Hard Sciences?" Scientometrics 112 (1): 607-53.

Bozeman, Barry. 2007. Public Values and Public Interest: Counterbalancing Economic Individualism. Public Management and Change Series. Washington, DC: Georgetown University Press.

Braxton, John M. 1983. "Department Colleagues and Individual Faculty Publication Productivity." The Review of Higher Education 6 (2): 115-28.

Brew, Angela, and Lisa Lucas. 2009. "Introduction: Academic Research and Researchers." In Academic Research and Researchers, 1-12. New York: Society for Research in Higher Education/Open University Press.

Bryman, Alan, and Emma Bell. 2011. Business Research Methods. 3rd ed. Cambridge: Oxford University Press.

Budescu, David V., and Mia Budescu. 2012. "How to Measure Diversity When You Must." Psychological Methods 17 (2): 215-27. 
Butler, Nick, Helen Delaney, and Sverre Spoelstra. 2015. "Problematizing 'Relevance' in the Business School: The Case of Leadership Studies." British Journal of Management 26 (4): 731-44.

Cameron, A. Colin, and Pravin K. Trivedi. 2013. Regression Analysis of Count Data. 2nd ed. Cambridge: Cambridge University Press.

Capano, Giliberto. 2011. “Government Continues to Do Its Job. A Comparative Study of Governance Shifts in the Higher Education Sector." Public Administration 89 (4): 1622-42.

Cartlidge, Edwin. 2010. "Italian Parliament Passes Controversial University Reforms." Science 330 (6010): 1462-63.

Chavarro, Diego, Puay Tang, and Ismael Ràfols. 2017. "Why Researchers Publish in Non-mainstream Journals: Training, Knowledge Bridging, and Gap Filling." Research Policy 46 (9): 1666-80.

Cheng, Ming. 2017. "Against a Managerialist Approach to Higher Education." University World News Global, February 17. http://www.universityworldnews.com/article.php?story=20170216075035683.

Clegg, Sue. 2008. "Academic Identities Under Threat?" British Educational Research Journal 34 (3): 329-45.

Cole, Jonathan R., and Harriet Zuckerman. 1984. "The Productivity Puzzle: Persistence and Changes in Patterns of Publication of Men and Women Scientists." Advances in Motivation and Achievements 2: 17-256.

Crane, Diana. 1965. "Scientists at Major and Minor Universities: A Study of Productivity and Recognition." American Sociological Review 30 (5): 699.

Creswell, John W. 1985. Faculty Research Performance, Lessons from the Sciences and Social Sciences. ASHE-ERIC Higher Education Report, no. 4, 1985. Washington, DC: Association for the Study of Higher Education.

Daraio, Cinzia, and Henk F. Moed. 2011. "Is Italian Science Declining?" Research Policy 40 (10): 1380-92.

Davies, Bronwyn, Michael Gottsche, and Peter Bansel. 2006. "The Rise and Fall of the Neo-liberal University." European Journal of Education 41 (2): 305-19.

Degn, Lise. 2016. "Academic Sensemaking and Behavioural Responses - Exploring How Academics Perceive and Respond to Identity Threats in Times of Turmoil." Studies in Higher Education April: 1-17.

Denis, Jean-Louis, Ewan Ferlie, and Nicolette Van Gestel. 2015. "Understanding Hybridity in Public Organizations." Public Administration 93 (2): 273-89.

European Commission. 2008. "Communication from the Commission to the Council and the European Parliament - Better Careers and More Mobility: A European Partnership for Researchers." Brussels. SEC, 1911.

Fabel, Oliver. 2008. "Editorial: Zum Schwerpunkt Forschungs-Rankings." Perspektiven Der Wirtschaftspolitik 9 (3): $252-53$.

Fox, Mary Frank. 1983. "Publication Productivity among Scientists: A Critical Review." Social Studies of Science 13 (2): $285-$ 305.

Frølich, Nicoline. 2011. "Multi-Layered Accountability. Performance-based Funding of Universities." Public Administration 89 (3): 840-59.

Fussy, Daniel Sidney. 2017. "Policy Directions for Promoting University Research in Tanzania." Studies in Higher Education January: 1-13.

George, Jennifer M., and Gareth R. Jones. 2012. Understanding and Managing Organizational Behavior. 6th ed. Boston: Pearson.

Goglio, Valentina, and Paolo Parigi. 2016. "An Institutional Mechanism to Reduce Internal Competition? A Hypothesis About the Diffusion of Satellite Universities in Italy." Studies in Higher Education 41 (8): 1495-1513.

Groot, Tom, and Teresa García-Valderrama. 2006. "Research Quality and Efficiency." Research Policy 35 (9): $1362-76$.

Guzzo, Richard A., and Marcus W. Dickson. 1996. "Teams in Organizations: Recent Research on Performance and Effectiveness." Annual Review of Psychology 47 (1): 307-38.

Hallett, Tim. 2010. "The Myth Incarnate: Recoupling Processes, Turmoil, and Inhabited Institutions in an Urban Elementary School." American Sociological Review 75 (1): 52-74.

Hansen, Thomas, and John M. Levine. 2009. "Newcomers as Change Agents: Effects of Newcomers' Behavioral Style and Teams' Performance Optimism." Social Influence 4 (1): 46-61.

Harrison, D. A., and K. J. Klein. 2007. "What's the Difference? Diversity Constructs as Separation, Variety, or Disparity in Organizations." Academy of Management Review 32 (4): 1199-1228.

Heppner, P. Paul, and Mary J. Heppner. 2004. Writing and Publishing Your Thesis, Dissertation, and Research: A Guide for Students in the Helping Professions. Belmont, CA: Thomson/Brooks/Cole.

Hmieleski, Keith M., and Michael D. Ensley. 2007. "A Contextual Examination of New Venture Performance: Entrepreneur Leadership Behavior, Top Management Team Heterogeneity, and Environmental Dynamism." Journal of Organizational Behavior 28 (7): 865-89.

Horta, Hugo, Vincent Dautel, and Francisco M. Veloso. 2012. "An Output Perspective on the Teaching-Research Nexus: An Analysis Focusing on the United States Higher Education System." Studies in Higher Education 37 (2): 171-87.

Huang, Yating, Sun-Keung Pang, and Shulin Yu. 2016. "Academic Identities and University Faculty Responses to New Managerialist Reforms: Experiences from China." Studies in Higher Education March: 1-19.

Knights, David, and Caroline A. Clarke. 2014. "It's a Bittersweet Symphony, This Life: Fragile Academic Selves and Insecure Identities at Work." Organization Studies 35 (3): 335-57.

Kok, Seng Kiat, and Claire McDonald. 2017. "Underpinning Excellence in Higher Education - An Investigation Into the Leadership, Governance and Management Behaviours of High-performing Academic Departments." Studies in Higher Education 42 (2): 210-31. 
Krücken, Georg. 2014. "Higher Education Reforms and Unintended Consequences: A Research Agenda." Studies in Higher Education 39 (8): 1439-50.

Leahey, Erin. 2006. “Gender Differences in Productivity." Gender \& Society 20 (6): 754-80.

Leahey, Erin. 2007. "Not by Productivity Alone: How Visibility and Specialization Contribute to Academic Earnings." American Sociological Review 72 (4): 533-61.

Lee, Sooho, and Barry Bozeman. 2005. "The Impact of Research Collaboration on Scientific Productivity." Social Studies of Science 35 (5): 673-702.

Lee, Soo Jeung, and Jisun Jung. 2017. "Work Experiences and Knowledge Transfer Among Korean Academics: Focusing on Generational Differences." Studies in Higher Education March: 1-26.

Leišytè, Liudvika. 2016. "New Public Management and Research Productivity - A Precarious State of Affairs of Academic Work in the Netherlands." Studies in Higher Education 41 (5): 828-46.

Lerner, J. S., and P. E. Tetlock. 1999. "Accounting for the Effects of Accountability." Psychological Bulletin 125 (2): $255-75$. Lewis, Jenny M. 2013. Academic Governance: Disciplines and Policy. New York: Routledge.

Lewis, Jenny M. 2014. "Individual and Institutional Accountability: The Case of Research Assessment." Australian Journal of Public Administration 73 (4): 408-16.

Long, J. Scott. 1997. Regression Models for Categorical and Limited Dependent Variables. 1st ed. Thousand Oaks, CA: SAGE.

Long, Rebecca G., William P. Bowers, Tim Barnett, and Michael C. White. 1998. "Research Productivity of Graduates in Management: Effects of Academic Origin and Academic Affiliation." Academy of Management Journal 41 (6): $704-14$.

Long, J. Scott, and Mary Frank Fox. 1995. "Scientific Careers: Universalism and Particularism." Annual Review of Sociology 21 (1): 45-71.

Lutter, Mark, and Martin Schröder. 2016. "Who Becomes a Tenured Professor, and Why? Panel Data Evidence from German Sociology, 1980-2013." Research Policy 45 (5): 999-1013.

MacIntosh, Robert, Nic Beech, Jean Bartunek, Katy Mason, Bill Cooke, and David Denyer. 2017. "Impact and Management Research: Exploring Relationships Between Temporality, Dialogue, Reflexivity and Praxis." British Journal of Management 28 (1): 3-13.

Madjar, Nora, Greg R. Oldham, and Michael G. Pratt. 2002. “There's No Place Like Home? The Contributions of Work and Nonwork Creativity Support to Employees' Creative Performance." Academy of Management Journal 45 (4): $757-67$.

Martin, B. R. 2011. “The Research Excellence Framework and the 'Impact Agenda': Are We Creating a Frankenstein Monster?" Research Evaluation 20 (3): 247-54.

Merton, Robert K. 1973. The Sociology of Science: Theoretical and Empirical Investigations. Chicago, IL: University of Chicago Press.

Ministero dell'Istruzione dell'Università e della Ricerca - Ufficio di Statistica. 2014. “Elaborazione Su Dati Anagrafe Nazionale Degli Studenti Universitari."

Nag, R., K. G. Corley, and D. A. Gioia. 2007. "The Intersection of Organizational Identity, Knowledge, and Practice: Attempting Strategic Change via Knowledge Grafting." Academy of Management Journal 50 (4): 821-47.

Nickson, MA Alicen. 2014. "A Qualitative Case Study Exploring the Nature of New Managerialism in UK Higher Education and Its Impact on Individual Academics' Experience of Doing Research." Journal of Research Administration 45 (1): 47.

O'Connor, Pat, and Clare O'Hagan. 2016. "Excellence in University Academic Staff Evaluation: A Problematic Reality?" Studies in Higher Education 41 (11): 1943-57.

Overman, Sjors, Agnes Akkerman, and René Torenvlied. 2016. "Targets for Honesty: How Performance Indicators Shape Integrity in Dutch Higher Education." Public Administration 94 (4): 1140-54.

Park, S. H., and M. E. Gordon. 1996. "Publication Records and Tenure Decisions in the Field of Strategic Management." Strategic Management Journal 17 (2): 109-28.

Parker, Edwin B., David Alfred Lingwood, and William J. Paisley, eds. 1968. Communication and Research Productivity in an Interdisciplinary Behavioral Science Research Area. Stanford, CA: Institute for Communication Research, Stanford University.

Pelz, Donald Campbell, and Frank M. Andrews. 1976. Scientists in Organizations: Productive Climates for Research and Development. Rev. ed. Ann Arbor: Institute for Social Research, University of Michigan.

Posner, Barry Z., and Warren H. Schmidt. 1993. "Values Congruence and Differences Between the Interplay of Personal and Organizational Value Systems." Journal of Business Ethics 12 (5): 341-47.

Powell, Kendall. 2016. "Does It Take Too Long to Publish Research?" Nature 530 (7589): 148-51.

Pugh, D. S., D. J. Hickson, C. R. Hinings, and C. Turner. 1968. “Dimensions of Organization Structure." Administrative Science Quarterly 13 (1): 65.

Rebora, Gianfranco, and Matteo Turri. 2013. "The UK and Italian Research Assessment Exercises Face to Face." Research Policy 42 (9): 1657-66.

Salancik, Gerald R., and Jeffrey Pfeffer. 1978. "A Social Information Processing Approach to Job Attitudes and Task Design." Administrative Science Quarterly 23 (2): 224.

Shin, Shung Jae, and Jing Zhou. 2003. "Transformational Leadership, Conservation, and Creativity: Evidence from Korea." Academy of Management Journal 46 (6): 703-14.

Somech, Anit, and Anat Drach-Zahavy. 2013. "Translating Team Creativity to Innovation Implementation." Journal of Management 39 (3): 684-708. 
Stewart, Greg L. 2006. "A Meta-Analytic Review of Relationships Between Team Design Features and Team Performance." Journal of Management 32 (1): 29-55.

Teelken, Christine. 2015. "Hybridity, Coping Mechanisms, and Academic Performance Management: Comparing Three Countries." Public Administration 93 (2): 307-23.

Tijssen, Robert J W. 2003. "Scoreboards of Research Excellence." Research Evaluation 12 (2): 91-103.

Tijssen, Robert J. W., Martijn S. Visser, and Thed N. van Leeuwen. 2002. "Benchmarking International Scientific Excellence: Are Highly Cited Research Papers an Appropriate Frame of Reference?" Scientometrics 54 (3): 381-97.

Van Der Wal, Zeger, Gjalt De Graaf, and Karin Lasthuizen. 2008. "What's Valued Most? A Comparative Empirical Study on the Differences and Similarities Between the Organizational Values of the Public and Private Sector." Public Administration 86 (2): 465-82.

Van Dooren, Wouter, and Steven Van de Walle. 2008. "Reality Is Merely an Illusion, Albeit a Persistent One: Introduction to the Performance Measurement Symposium." International Review of Administrative Sciences 74 (4): 531-34.

Van Raan, A. F. J. 1998. "The Influence of International Collaboration on the Impact of Research Results." Scientometrics 42 (3): 423-28.

Vogelgesang, Lori J., Nida Denson, and Uma M. Jayakumar. 2010. "What Determines Faculty-engaged Scholarship?" The Review of Higher Education 33 (4): 437-72.

Webber, Sheila Simsarian, and Lisa M. Donahue. 2001. "Impact of Highly and Less Job-related Diversity on Work Group Cohesion and Performance: A Meta-analysis." Journal of Management 27 (2): 141-62.

Wernimont, Paul F., and John P. Campbell. 1968. "Signs, Samples, and Criteria." Journal of Applied Psychology 52 (5): $372-$ 76.

Williamson, lan O., and Daniel M. Cable. 2003. "Predicting Early Career Research Productivity: The Case of Management Faculty." Journal of Organizational Behavior 24 (1): 25-44.

Witesman, Eva, and Lawrence Walters. 2014. "Public Service Values: A New Approach to the Study of Motivation in the Public Sphere." Public Administration 92 (2): 375-405.

Wright, Bradley E. 2007. "Public Service and Motivation: Does Mission Matter?" Public Administration Review 67 (1): $54-64$.

Xie, Yu, and Kimberlee A. Shauman. 1998. "Sex Differences in Research Productivity: New Evidence About an Old Puzzle." American Sociological Review 63 (6): 847-70.

Zuckerman, Harriet. 1967. "Nobel Laureates in Science: Patterns of Productivity, Collaboration, and Authorship." American Sociological Review 32 (3): 391-403. 